\title{
Lignin-derived Polyphenolic Composition with Ammonium Molybdate BP-C2
}

National Cancer Institute

\section{Source}

National Cancer Institute. Lignin-derived Polyphenolic Composition with Ammonium

Molybdate BP-C2. NCI Thesaurus. Code C162877.

An orally bioavailable solution containing lignin-derived benzene-polycarboxylic acids mixed with ammonium molybdate, with potential use as an adjuvant and with potential radioprotective and regenerative activities. Upon oral administration, lignin-derived polyphenolic composition with ammonium molybdate BP-C2 is also able to stimulate the innate immune system and upregulates a variety of cytokines including interferon (IFN), tumor necrosis factor-alpha (TNF-alpha), granulocyte macrophage-colony stimulating factor (GM-CSF), and various interleukins (ILs) such as IL-6, IL-22 and IL-25, and induces the production of innate lymphoid cells. BP-C2 stimulates the production of intestinal epithelial cells thereby protecting the gastrointestinal (Gl) tract against Gl-induced cytotoxic side effects caused by certain anti-tumor agents. Additionally, BP-C2 scavenges free radicals, inhibits lipid oxidation, and protects cells against radiationinduced damage. Molybdenum, an essential micronutrient, acts as a cofactor in multiple detoxification system enzymes. BP-C2 may also stimulate the production of hematopoietic progenitor cells, thereby correcting hematological abnormalities such as anemia, thrombocytopenia and neutropenia, which are also caused by certain anti-cancer agents. 